EDITORIAL

\section{Capitalism and Commodities: My Two Cents}

\author{
H.J. Cloft, Senior Editor
}

W e neurointerventionalists have a tendency to see ourselves as master craftsmen, using only the finest tools to perform at the highest levels of excellence. However, the finest tools often come at a premium price. To control rising health care costs, we will ultimately need to become master clinicians who can care for a patient who comes to us with a routine problem in a routine manner that does not break the bank. A recent article in the New England Journal of Medicine argues that when physicians consider costs, they are indeed serving the real interests of individual patients. ${ }^{1}$ An occasional patient may have a very difficult problem, requiring an endovascular procedure that is financially analogous to a heart-lung transplant. However, we should recognize that most of our patients are undergoing routine procedures more analogous to an appendectomy. I do not dispute that every human being is special and that what we do requires a lot of training, skill, and individualized attention to the patient, but more than 20 years after the invention of the Guglielmi detachable coil (Boston Scientific, Natick, Massachusetts), we ought to have reached the point where most of our endovascular aneurysm cases are routine for a skilled operator working with mature devices.

I would submit that to deny that our typical procedure is routine is to deny the progress we have made as a specialty. Our specialty no longer consists of a few pioneers trying to improvise new therapies while using non-FDA-approved materials. Rather, we have reached maturity as a specialty, with professional societies that have many members and annual meetings on national and international levels and support from an expanding industry that produces devices specifically tailored to our needs. It is difficult to reconcile a self-admiring perception of ourselves as providing "cutting edge" technology to every single patient with the reality that at some point, our success as a specialty hinges on our having reached the point of providing excellent care routinely with mature products that have become commodities.

Many and probably most of the endovascular devices we use today are mature technology. There will undoubtedly continue to be incremental improvement in devices and even revolutionary changes, but these do not need to be always accompanied by a price premium. When we buy a new television, computer, or camera, we are often concerned that next year we could buy a better one and that it will actually be cheaper. The same could also occur with endovascular devices in a healthy competitive market place. In the orthopedic surgery implant industry, companies are being founded on the premise of providing low-cost implants to hospitals, including ROG Sports Medicine (Orland Park, Illinois), Emerge Medical (Denver, Colorado), and Orthopedic Implant Company (Reno, Nevada), whose Web sites explicitly express a mission of lowering device costs. Highlighting the problem of

http://dx.doi.org/10.3174/ajnr.A3559 rising implant costs, the American Academy of Orthopedic Surgeons published a position statement in 2009 titled "Value Driven Use of Orthopedic Implants" and declared that "orthopaedic surgeons have an important role in the appropriate and value-driven utilization of implantable orthopaedic devices."

In the past, physicians made the majority of the device-purchasing decisions. Physicians have often made device choices without regard for pricing, which creates the moral hazard that arises when we are spending someone else's money. If the people making the purchase decisions are not sensitive to price, then the capitalist market malfunctions and prices remain high. However, physicians increasingly have less autonomy with device purchases. Physicians as well as hospitals are feeling pressure from declining reimbursements and increased operational costs, resulting in a trend of physicians integrating into hospital-affiliated practices. The American College of Cardiology recently released data from its Practice Census projecting that by the end of 2012, more than half of all cardiologists would be employed by hospitalbased systems, which is up from $30 \%$ in $2010 .^{3}$ Orthopedic surgeons are also increasingly becoming hospital employees. ${ }^{4}$ I am not aware of such a shift toward hospital employment of neurointerventionalists, but perhaps that is in our future. Even if we are not directly employed by a hospital, it is increasingly clear that physicians and hospitals are dependent on each other's financial viability. This is a significant change from the past when physicians were often indifferent or antagonistic to a hospital's financial concerns. Supplies and devices accounted for $24 \%$ of the increase in hospital costs per discharge from 2001 to $2006,{ }^{5}$ so it makes sense that hospitals are beginning to partner with physicians to target supply and device expenses.

There is much already written about the problem of the rapidly increasing cost of health care in the United States and the burden that places on society and the government. With specific relevance to our specialty, recent studies have shown that the costs of hospitalization substantially exceed Medicare payments for endovascular therapy of unruptured cerebral aneurysm, ${ }^{6}$ acute ischemic stroke, ${ }^{7}$ and carotid stenosis. ${ }^{8}$ In the case of unruptured cerebral aneurysm treatment, it is not at all unusual for the cost of devices to consume the entire diagnosis related groups-based hospital Medicare payment, ${ }^{9}$ leaving nothing else to cover the remaining hospital expenses. Therefore, the hospital loses money taking care of our patients. This situation is particularly striking with the introduction of the Pipeline Embolization Device (ev3 Neurovascular, Irvine, California), which has a retail price tag that is shockingly similar to the 2013 average diagnosis related groupsbased payment of $\$ 12,490$ for hospitalization for uncomplicated therapy for an unruptured cerebral aneurysm. With the aging population and the Affordable Care Act, essentially everyone's payer mix is going to get worse (ie, a growing fraction of patients in your practice will be reimbursed at government rates). I am offering my perspective as a practitioner in the United States, but an international need for affordability is becoming increasingly obvious as neurointerventional technology continues to expand into emerging markets like China and India, because citizens of those countries typically pay directly for their own devices.

People in the neurointerventional field often speak of "partnering with industry." In the past, that partnership has consisted 
of working with the medical device industry to get the tools that we need to treat patients and that has indeed been a successful partnership. Our industry partners could now move beyond the ongoing cycle of small incremental engineering advances in relatively stable technologies and consequent escalating price increases to a new paradigm of gaining a market share by selling less expensive commodities in volume. A competitive-device marketplace is the key to a future that is financially viable for patients, physicians, hospitals, and the medical device industry. Market forces are coming into place that will make it conceivable to start medical device companies with the specific intent of helping hospitals save money. Device vendors that do not try to help hospitals save money may soon find it difficult to have value added.

\section{REFERENCES}

1. Rosenbaum L, Lamas D. Cents and sensitivity-teaching physicians to think about costs. N Engl J Med 2012;367:99-101

2. American Academy of Orthopedic Surgeons. Position statement: value driven use of orthopaedic implants. http://www.aaos.org/ about/papers/position/1104.asp. Accessed February 28, 2013
3. Duffy PL. Hospital employment: how \& why my practice integrated with the local hospital system. Society for Cardiovascular Angiography and Interventions News \& Highlights. Winter 2012;9-10

4. Bozic KJ, Roche M, Agnew SG. Hospital-based employment of orthopaedic surgeons-passing trend or new paradigm? AOA critical issues. J Bone Joint Surg Am 2012;94:e59

5. Maeda JL, Raetzman SO, Friedman BS. What hospital inpatient services contributed the most to the 2001-2006 growth in the cost per case? Health Serv Res 2012;47:1814-35

6. Brinjikji W, Kallmes DF, Rabinstein AA, et al. Hospitalization costs for patients with acute ischemic stroke treated with endovascular embolectomy in the United States. Stroke 2011;42:3271-73

7. Brinjikji W, Rabinstein AA, Cloft HJ. Hospitalization costs for acute ischemic stroke patients treated with intravenous thrombolysis in the United States are substantially higher than Medicare payments. Stroke 2012;43:1131-33

8. McDonald RJ, Kallmes DF, Cloft HJ. Comparison of hospitalization costs and Medicare payments for carotid endarterectomy and carotid stenting in asymptomatic patients. AJNR Am J Neuroradiol 2012;33:420-25

9. Cloft HJ. Coils and cash: what coil vendors don't want you to know. AJNR Am J Neuroradiol 2009;30:1276-77 